\title{
Pharmacokinetics of Cymbopogon citratus Infusion in Rats after Single Oral Dose Administration
}

\author{
Gustavo Costa ${ }^{1 *}$, Ana Fortuna ${ }^{1,2}$, Daniela Gonçalves ${ }^{1,2}$, Isabel Vitória Figueiredo ${ }^{2,3}$, \\ Amílcar Falcão ${ }^{1,2}$ and Maria Teresa Batista ${ }^{1}$ \\ ${ }^{1}$ Center for Neurosciences and Cell Biology, University of Coimbra, 3004-517 Coimbra, Portugal \\ ${ }^{2}$ Laboratory of Pharmacology, Faculty of Pharmacy, University of Coimbra, Pólo das Ciências da Saúde, Azinhaga de Santa Comba, 3000-548 Coimbra, \\ Portugal \\ ${ }^{3}$ Institute for Biomedical Imaging and Life Sciences, University of Coimbra, Portugal
}

\begin{abstract}
Received: January 19, 2017; Accepted: March 15, 2017; Published: April 21, 2017
*Corresponding author: Gustavo Costa, Center for Neurosciences and Cell Biology, University of Coimbra, $3004-517$ Coimbra, Portugal, Tel: +351 239 488 400; Fax: +351 239488 503; E-mail: costagff@gmail.com
\end{abstract}

\begin{abstract}
Cymbopogon citratus, commonly known as lemongrass, is a tropical herb used in worldwide traditional medicine for centuries. Studies previously conducted by our team demonstrated its antioxidant and anti-inflammatory effects, and recently, the antiinflammatory potential was also observed in vivo. However, little is known about its pharmacokinetics. The current study aimed at obtaining, for the first time, the pharmacokinetic profile of lemongrass infusion after a single dose oral administration to rats.

All in vivo experimental procedures were approved by the Portuguese Veterinary General Division. Male Wistar rats were administered with a single oral dose of lemongrass infusion $(68.24$ $\mathrm{mg} / \mathrm{kg}$ ) and aliquots of plasma were collected at $0.5,1,1.5,2,4,8$, 12 and $24 \mathrm{~h}$ post-dosing. Liver and kidney samples were collected at $1,2,4,8$ and 24 h post-dosing. Plasma and tissues homogenates were processed and luteolin (LUT), luteolin 7-0-glucuronide (L7G), chrysoeriol (CHR), diosmetin (DIO) and luteolin 3'-0-sulphate (L3'S) were quantified employing a RP-HPLC-DAD method. The mean concentration-time profiles obtained were analyzed by a noncompartmental pharmacokinetic analysis using the WinNonlin ${ }^{\circledR}$.

The pharmacokinetic studies revealed the presence of LUT, L7G, CHR, DIO and L3'S. L7G and L3'S were rapidly detected, with maximum plasma concentrations at $30 \mathrm{~min}$ after oral administrations. The concentration-time profile of liver samples evidenced compounds undetected in plasma: LUT, CHR and DIO. L7G, CHR and L3'S were detected in the liver from the first hour and stayed in the tissue until at least $24 \mathrm{~h}$. The kidney concentration-time profile revealed the presence of the same compounds detected in plasma.

The pharmacokinetic analysis showed that the compounds present in lemongrass infusion are not present in plasma, liver or kidneys. On the other hand, L7G and L3'S were the major metabolites found in plasma and tissues, suggesting that lemongrass polyphenols are promptly metabolized in vivo and their metabolites may be the ones responsible for the anti-inflammatory activity of C. citratus, when orally administered.
\end{abstract}

Keywords: Cymbopogon citratus; Lemongrass; Flavonoids; Pharmacokinetics; In vivo; C. citratus

\section{Introduction}

Cymbopogon citratus (DC.) Stapf is a tropical herb of the Poaceae family from Southeast Asia, commonly known as lemongrass. Studies previously conducted demonstrated its hypoglycemic, hipolypidemic, anxiolytic, sedative, antioxidant and anti-inflammatory effects [1-5]. Some researchers have studied diverse-origin samples of lemongrass regarding their phenolic composition and antioxidant and anti-inflammatory properties [6-9]. In the past years, the phenolic composition of lemongrass infusion was described: 3-feroylquinic acid, neochlorogenic acid, chlorogenic acid, p-coumaric acid, carlinoside, isoschaftoside, isoorientin, cynaroside, veronicastroside, luteolin 7-0-neohesperidoside, kurilensin A and cassiaoccidentalin B [10]. We also demonstrated that flavonoids, such as luteolin and apigenin glycosides, and tannins strongly contributed to antioxidant and anti-inflammatory properties of an essential oilfree infusion from lemongrass [6,11-15]. Very recently, the antiinflammatory and analgesic potential of lemongrass infusion was also revealed in vivo by our research group [16]. These activities were ascribed tomono- and polymeric flavonoid-enriched fractions of the crude extract, in which flavones 0 - and mainly C-glycosides and flavanic tannins, respectively, were identified, suggesting, therefore, a straight relationship between these phenolic compounds and their properties aforementioned.

Biological effects of flavonoids imply them to be bioavailable and to effectively reach target tissues. Thus, a number of studies have been conducted in order to investigate the metabolism of naturally occurring flavonoids, focusing particularly on the role of the gut microflora in the metabolic transformation of flavonoids $[17,18]$. Accordingly, following the ingestion of flavonoid O-glycosides and before their intestinal absorption, the corresponding sugar moieties (as in quercetin 3-0-glucoside) are cleaved from the phenolic backbone by enzymes expressed at the enterocyte membrane such as lactase phlorizin hydrolase (LPH) or cytosolic enzymes such as Betaglucosidase (CBG), which hydrolyze glycosylated flavonoids, allowing the formed aglycones to enter epithelial cells by passive 
diffusion [19]. However, flavonoids linked to a rhamnosemoiety must reach the colon to be hydrolyzed by the $\alpha$-rhamnosidases secreted by the colon microbiota (as Bifidobacterium dentium), in order to be absorbed [18]. Once the final derivative or theaglycone have been absorbed, they suffer phase II metabolism at enterocyte level; these reactions include methylation at $\mathrm{C}^{\prime}$ ' or C4' by catechol-0-methyltransferase (COMT), sulfation at C3', C4', C5, or C7 by sulfotransferases (SULT) and/or glucuronidation by UDP-glucuronosyltransferases. Afterwards, these products enter the blood stream by the portal vein, reaching the liver, where they may be subjected to more phase II metabolism, hence becoming conjugated and transported to the bloodstream again until they are secreted in urine [20-22]. Some of the liver conjugates are then excreted as bile components and back into the intestine (enterohepatic recirculation), while deconjugated compounds are regenerated by gut microbial enzymes before being reabsorbed again [23]. The unabsorbed metabolites are eliminated via faeces. All these conjugation mechanisms are highly efficient, and free aglycones are generally absent or present in low concentrations in plasma after nutritional doses [18].

In opposition, few studies have been performed regarding the absorption, tissue distribution, metabolism and excretion of flavone $C$-glycosides $[24,25]$ in spite of the importance of the biodisposition of flavone $C$-glycosides after oral administration, which determines their potential benefit in pharmacotherapy or nutrition. In addition to the structural and physico-chemical attributes of the parent compounds, their pharmacokinetics is essential because determines their biological effects. However, the current understanding of absorption and biodisposition is limited to a small number of dietary flavonoids and few studies referred to the metabolism of flavone C-glycosides [26-28]. A single oral dose administration of a Crataegus crude extract evidenced that only the intact forms of vitexin $\mathrm{O}$-glucoside and $\mathrm{O}$-rhamnoside were detected in plasma, tissues, urine and bile and that deconjugation of C-glycosylflavone was not a prerequisite for its absorption in rats [27]. Similarly, when orally administered, puerarin, another C-glycosyl flavone, was also rapidly absorbed from the intestine without being previously metabolized [29]. High recovery of administered vitexin 4"-0-glucoside and 2"-0-rhamnoside in faeces indicated that the efficient absorption of these molecules from the gastrointestinal tract of rats was low. In fact, it was reported that vitexin 2"-O-rhamnoside has limited gastrointestinal absorption with an oral bioavailability of only $3.57 \%[28,30]$. A recent work investigated the pharmacokinetic and excretion profile of Swertia pseudochinensis extract after its oral administration to rats and determined three secoiridoid glycosides and three flavonoid glycosides in plasma, bile, urine and faeces [25]. This study also found that, although both groups of components rapidly achieved the maximum peak concentration in plasma $\left(\mathrm{C}_{\max }\right)$ with a corresponding time to reach $\mathrm{C}_{\max }\left(\mathrm{T}_{\max }\right)$ between 10 and $40 \mathrm{~min}$, the bioavailability of the secoiridoid glycosides was significantly higher than that of the flavonoid glycosides and the elimination half-life $\left(\mathrm{T}_{1 / 2}\right)$ ranged from 58.4 to $263.0 \mathrm{~min}$. These results demonstrated that both the absorption and elimination processes of all analytes were fast, and mainly by urine excretion.
The objective of the current study was to investigate, for the first time, the pharmacokinetic profile of phenolic acids and flavonoids in rats after oral administration of a single dose of $C$. citratus infusion which has very recently revealed antiinflammatory activity in vivo [16].

\section{Materials and Methods}

\section{Chemicals and drugs}

Isovitexin (ISV), isoorientin (ISO), luteolin (LUT), luteolin 7-0-glucuronide (L7G), chrysoeriol (CHR) and diosmetin (DIO) were purchased from Extrasynthese ${ }^{\circledR}$ (Lyon, France). Caffeic acid (CAF) and p-coumaric acid (COU) were acquired from SigmaAldrich $^{\circledR}$ (St. Louis, MO, USA). Rutin (RUT), sodium chloride, potassium chloride, disodium phosphate, monopotassium phosphate, formic acid, acetone, n-hexane andmethanol (HPLC gradient grade) were purchased from Merck $^{\circledR}$ (Darmstadt, Germany). Ultra-pure water (HPLC grade $>18 \mathrm{M}$; homemade) was prepared by means of a MilliQ water apparatus from Millipore ${ }^{\circledR}$ (Milford, MA, USA). Isoflurane (Isoflo ${ }^{\circledR}$ ) was acquired to Siloal, S.A.

\section{Plant Material and Extraction}

Dry leaves of Cymbopogon citratus were acquired from Ervital ${ }^{\circledR}$ (Mezio, Castro Daire, and Portugal). Cymbopogon citratus was bred in the region of Mezio, Castro Daire (Portugal) anda voucher specimen was deposited in the Herbarium of Aromatic and Medicinal Plants of the Faculty of Pharmacy - University of Coimbra (A. Figueirinha 0109). The identity of the plant was confirmed by J. Paiva (Life Sciences Department, University of Coimbra, Portugal).

A lipid- and essential oil-free infusion was prepared as previously described [6]. The infusion was obtained by adding $150 \mathrm{~mL}$ of boiling water to $5 \mathrm{~g}$ of powdered plant material, the mixture being kept hot and left to stand for $15 \mathrm{~min}$. The extract was then washed with $n$-hexane (1:1) three times to eliminate the lipophilic compounds and filtered under vacuum, concentrated in a rotavapor and freeze-dried. This freeze-dried extract (CcI) was kept at $-40^{\circ} \mathrm{C}$, until further use.

\section{In vivo pharmacokinetic studies}

All the animal experiments were conducted in accordance with the European Directive (2010/63/EU) for animal experiments and approved by the Portuguese Veterinary General Division.

Adult male Wistar rats (330-380g) were obtained from Charles River (Barcelona, Spain), maintained under controlled environmental conditions (temperature $20 \pm 2 \stackrel{\circ}{\circ} \mathrm{C}$; relative humidity $55 \pm 5 \%$; $12 \mathrm{~h}$ light/dark cycle)and receiving a standard rodent diet (4RF21, Mucedola ${ }^{\circledR}$, Italy) during almost all experimental procedures and tap water ad libitum. At the night before CcI administration, animals were anesthetized with isoflurane and their lateral tail vein was cannulated by inserting the Introcan ${ }^{\circledR}$ Certo IV indwelling cannula (22 G; $0.9 \times 2.5 \mathrm{~mm}$ ) for serial blood sampling. The rats fully recovered from anesthesia overnight, and were fasted for $12-14 \mathrm{~h}$ before CcI administration 
with free access to water. An additional fasting period ( $4 \mathrm{~h}$ postdose) was considered to avoid the effect of food on the oral bioavailability. A single-dose $(68.24 \mathrm{mg} / \mathrm{kg})$ of a CcI aqueous solution was administered by oral gavage to male Wistar rats (4 $\mathrm{mL} / \mathrm{kg}$ of body weight). The dose of CcI was calculated based on the traditionally used doses, and taking into account the Food and Drug Administration (FDA) Guidance for Industry on conversion of animal doses to human equivalent doses according to body surface area [31].

In the plasma pharmacokinetic study, six $\operatorname{rats}(n=$ 6) were treated with the single-dose of CcI extract aqueous solution $(68.24 \mathrm{mg} / \mathrm{kg}$, p.o.) and multiple serial blood samples (approximately $0.3 \mathrm{~mL}$ ) were collected through the cannula into heparinized tubes at $0.5,1,1.5,2,4,8,12$ and $24 \mathrm{~h}$ post-dosing. Blood sampling was conducted in conscious and freely moving rats, which were appropriately restrained only at the moment of blood collection. Blood samples were immediately centrifuged at $3000 \mathrm{~g}$ for $10 \mathrm{~min}\left(4^{\circ} \mathrm{C}\right)$ to separate the plasma, which was stored at $-80^{\circ} \mathrm{C}$ until analysis.

In the tissue pharmacokinetic studies, liver and kidneys were harvested, after decapitation and exsanguination under anesthesia, at 1, 2, 4, 8 and $24 \mathrm{~h}$ following CcI administration at the same dose of plasma pharmacokinetic study ( $n=2$, per time). The organs were excised and stored at $-80^{\circ} \mathrm{C}$; the tissues were weighed and homogenized in phosphate buffer saline (PBS) $\mathrm{pH}$ 7.4 ( $4 \mathrm{~mL}$ per gram of tissue) before analysis.

\section{Samples analysis}

Concentrations of analytes in plasma and tissues (liver and kidneys) were determined by using a solid-phase extraction procedure followed by a reversed-phase high performance liquid chromatography (HPLC) analysis, according to a previously validated method with slight modifications [10].

Briefly, $20 \mu \mathrm{L}$ of a $50 \%$ methanolic solution of internal standard (RUT) $(100 \mu \mathrm{g} / \mathrm{mL})$ was added to an aliquot of rat plasma sample $(100 \mu \mathrm{L})$ or tissue homogenate supernatant sample $(1 \mathrm{~mL})$ and mixed with $400 \mu \mathrm{L}$ of PBS buffer. Afterwards, the pre-treated sample was subjected to a solid-phase extraction (SPE) on the Oasis ${ }^{\circledR}$ HLB (30 mg, $1 \mathrm{~mL}$ ) cartridge (Waters ${ }^{\circledR}$, Milford, MA, USA), which was previously conditioned with $1 \mathrm{~mL}$ of $0.5 \%$ formic acid in methanol followed by $1 \mathrm{~mL}$ of $0.5 \%$ aqueous formic acid. The loaded cartridge was subsequently submitted to $-60 \mathrm{kPa}$ and washed four times with $1 \mathrm{~mL}$ of $0.5 \%$ aqueous formic acid. After drying the sorbent under vacuum for $5 \mathrm{~min}$, analytes were eluted with $1 \mathrm{~mL}$ of methanol-acetone (50:50, v/v) using a gentle vacuum. The eluate was evaporated to dryness at $40^{\circ} \mathrm{C}$ in a vacuum oven and reconstituted with $150 \mu \mathrm{L}$ of water-methanol (50:50, v/v) by vortexing and ultrasonication. At last, $100 \mu \mathrm{L}$ of the final mixture were injected into the chromatographic system.

HPLC analyses were performed according to Costa et al.[10], by using a chromatograph equipped with a diode-array detector (DAD) (Gilson ${ }^{\circledR}$ Electronics SA, Villiers le Bel, France). The studies were carried out on a Spherisorb S5 ODS-2 column ( $250 \times 4.6$ mm i.d.; particle size, $5 \mu \mathrm{m}$; Waters ${ }^{\circledR}$ Corp., Milford, MA, USA) at $25^{\circ} \mathrm{C}$ and a Nucleosil C18 guard cartridge $(30 \times 4$ mm i.d.; particle size, $5 \mu \mathrm{m}$; Macherey-Nagel, Düren, Germany). A mobile phase of $5 \%(\mathrm{v} / \mathrm{v})$ aqueous formic acid (A) and methanol (B) was used with a discontinuous gradient: 5-15\% B (0-10 min.), 15$30 \%$ B (10-15 min.), 30-35\% B (15-25 min.), 35-50\% B (25-35 $\mathrm{min}$.) and $50-80 \% \mathrm{~B}(35-40 \mathrm{~min}$.), followed by an isocratic elution for $20 \mathrm{~min}$., at a flow rate of $1 \mathrm{~mL} / \mathrm{min}$. An injection volume of 100 $\mu \mathrm{L}$ was used for all standards and samples. Chromatographic profiles were acquired in the wavelength range $200-600 \mathrm{~nm}$, and recorded at 280 and $320 \mathrm{~nm}$. The quantification of each compound was achieved through the absorption at $320 \mathrm{~nm}$. Data treatment was carried out with Unipoint ${ }^{\circledR} 2.10$ software $\left(\right.$ Gilson $\left.^{\circledR}\right)$. The main partial validation parameters of the analytical method employed were in agreement with the international guidelines [32,33] and are summarized in Table 1. 
Table 1: Validation parameters of the HPLC method employed for the quantification of caffeic acid (CAF), $p$-coumaric acid (COU), isovitexin (ISV), isoorientin (ISO), luteolin (LUT), luteolin 7-O-glucuronide (L7G), chrysoeriol (CHR) and diosmetin (DIO) in plasma, liver and kidney homogenate supernatants ( $n=3$ )

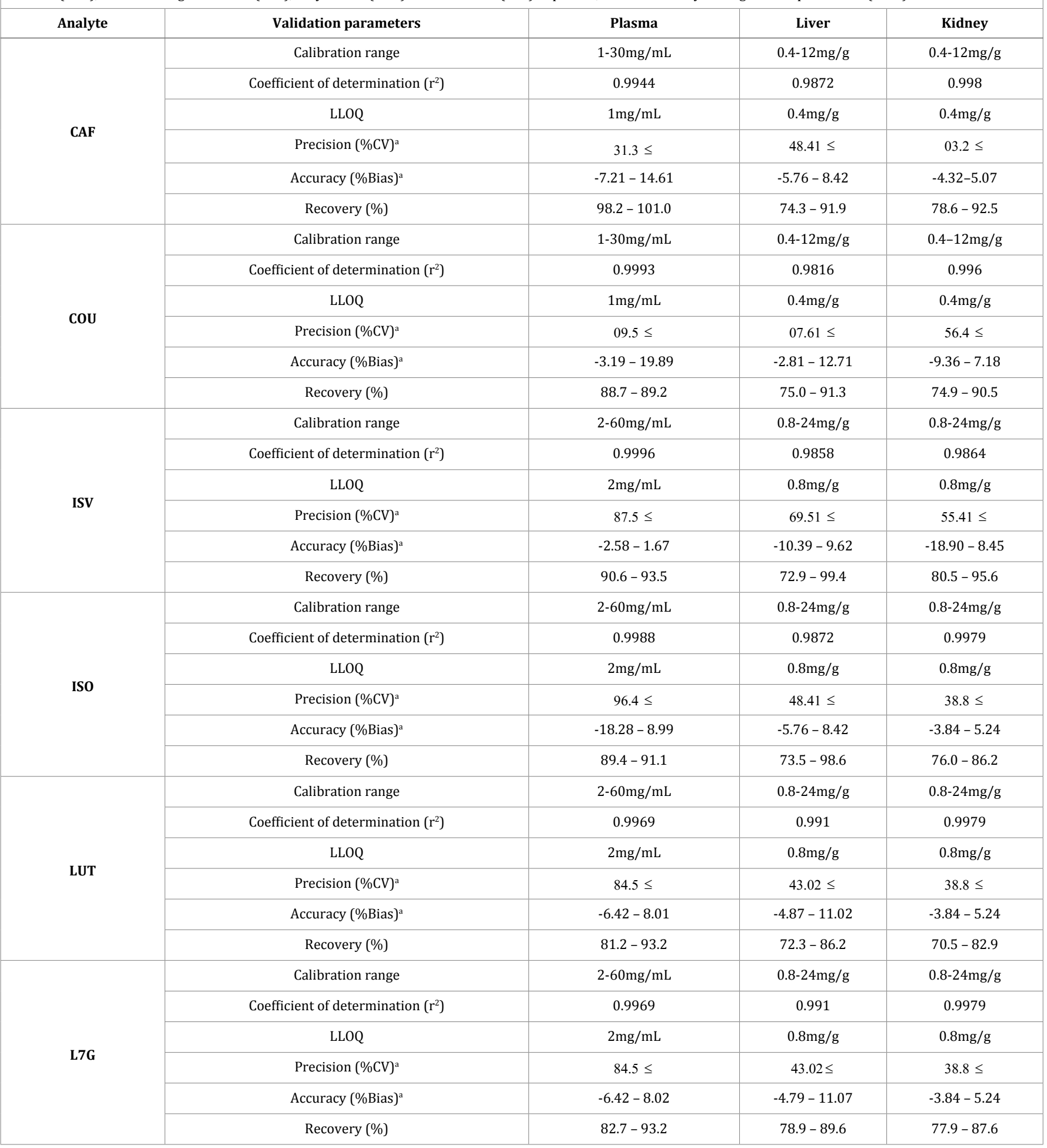




\begin{tabular}{|c|c|c|c|c|}
\hline \multirow{6}{*}{ CHR } & Calibration range & $2-60 \mathrm{mg} / \mathrm{mL}$ & $0.8-24 \mathrm{mg} / \mathrm{g}$ & $0.8-24 \mathrm{mg} / \mathrm{g}$ \\
\hline & Coefficient of determination $\left(\mathrm{r}^{2}\right)$ & 0.9969 & 0.991 & 0.9979 \\
\hline & LLOQ & $2 \mathrm{mg} / \mathrm{mL}$ & $0.8 \mathrm{mg} / \mathrm{g}$ & $0.8 \mathrm{mg} / \mathrm{g}$ \\
\hline & Precision $(\% \mathrm{CV})^{\mathrm{a}}$ & $84.5 \leq$ & $43.02 \leq$ & $38.8 \leq$ \\
\hline & Accuracy $\left(\%\right.$ Bias) ${ }^{a}$ & $-6.43-8.01$ & $-4.73-11.08$ & $-3.84-5.23$ \\
\hline & Recovery (\%) & $82.9-92.6$ & $80.2-86.2$ & $79.2-83.5$ \\
\hline \multirow{6}{*}{ DIO } & Calibration range & $2-60 \mathrm{mg} / \mathrm{mL}$ & $0.8-24 \mathrm{mg} / \mathrm{g}$ & $0.8-24 \mathrm{mg} / \mathrm{g}$ \\
\hline & Coefficient of determination $\left(\mathrm{r}^{2}\right)$ & 0.9969 & 0.991 & 0.9979 \\
\hline & LLOQ & $2 \mathrm{mg} / \mathrm{mL}$ & $0.8 \mathrm{mg} / \mathrm{g}$ & $0.8 \mathrm{mg} / \mathrm{g}$ \\
\hline & Precision $(\% \mathrm{CV})^{\mathrm{a}}$ & $84.5 \leq$ & $43.02 \leq$ & $38.8 \leq$ \\
\hline & Accuracy $(\% \text { Bias })^{a}$ & $-6.43-8.00$ & $-4.78-11.06$ & $-3.84-5.24$ \\
\hline & Recovery (\%) & $84.9-94.0$ & $79.2-84.3$ & $80.3-82.9$ \\
\hline
\end{tabular}

HPLC-PDA-ESI/MSn analysis, based on a previously optimized method [34], was performed in a Surveyor ${ }^{\circledR}$ liquid chromatography hyphenated to a photo-diode-array detector (PDA) (Surveyor ${ }^{\circledR}$ ) and a Finnigan ${ }^{\circledR}$ LCQ mass spectrometer (San Jose, CA, USA) equipped with an API-ES ionization chamber. Separation was performed on a Spherisorb ${ }^{\circledR}$ ODS-2 C18 reverse phase column, $150 \times 2.1 \mathrm{~mm}$ i.d. and particle size of $3 \mu \mathrm{m}$ (Waters ${ }^{\circledR}$ Corporation, Milford, Massachusetts, USA) and a Spherisorb ${ }^{\circledR}$ ODS-2 guard cartridge C18 (10 x $4.6 \mathrm{~mm}$ i.d. and particle size of $5 \mu \mathrm{m}$; Waters ${ }^{\circledR}$ Corporation, Milford, Massachusetts, USA) at $25^{\circ} \mathrm{C}$, using $2 \%$ aqueous formic acid (A) and methanol (B) as mobile phase. The gradient profile used was 5-15\% B (0-10 min), 15-30\% B (10-15 min), 30-35\% B (15-25 $\mathrm{min}$ ), $35-50 \%$ B (25-35 min), 50-80\% B (35-40 min) and 80\% B (40-60 min), isocratically, at a flow rate of $0.2 \mathrm{~mL} / \mathrm{min}$. The first detection was done with the PDA detector in a wavelength range of 200-600 nm, followed by a second detection in the mass spectrometer. Mass analyses were obtained in the negative ion mode. The mass spectrometer was programmed to perform three consecutive scans: full mass MS1 (m/z 160-1300), MS² of the most abundant ion in MS1, and MS3 of the most abundant ion in $\mathrm{MS}^{2}$. Source voltage was $4.5 \mathrm{kV}$ and capillary voltage and temperature were $-10 \mathrm{~V}$ and $250^{\circ} \mathrm{C}$, respectively. Nitrogen was used as sheath gas at flow rate of 20 arbitrary units. The normalized energy of collision was $45 \%$, using helium as collision gas.

\section{Pharmacokinetic analysis}

The plasma concentration versus time data for each analyte obtained from each individual rat was submitted to a non compartmental pharmacokinetic analysis using the WinNonlin ${ }^{\circledR}$ version 5.2. (Pharsight Co, Mountain View, CA, USA).

The $\mathrm{C}_{\max }$ in plasma and tissues of each analyte and the corresponding $\mathrm{T}_{\text {max }}$ were directly derived from the experimental data obtained. The remaining pharmacokinetic parameters evaluated included: the area under the drug concentration time- curve (AUC) from time zero to the last sampling time at which quantifiable drug concentrations were determined (AUC $0^{\circledR} \mathrm{t}$ ), calculated by the linear trapezoidal rule; the AUC from time zero to infinite (AUCO $\left.{ }^{\circledR i n f}\right)$ that was calculated from AUCt $+\left(\mathrm{C}_{\text {last }} /\right.$ $\mathrm{k}_{\mathrm{el}}$ ), where $\mathrm{C}_{\text {last }}$ is the last quantifiable concentration and $\mathrm{k}_{\mathrm{el}}$ is the apparent elimination rate constant estimated by log-linear regression of the terminal segment of the concentration-time profile; the apparent terminal elimination half-life $\left(\mathrm{T}_{1 / 2}\right)$ and the mean residence time (MRT).

\section{Results and Discussion}

The developed method was validated for eight different compounds: CAF, COU, ISV, ISO, LUT, L7G, CHR and DIO. L7G, L3'S, LUT, CHR and DIO were identified by HPLC-PDA-ESI/MSn. All compounds presented UV spectra characteristic of luteolin derivatives, with $\lambda_{\max }$ at 251-255 and 344-349 nm. L7G ([M - H]- at $\mathrm{m} / \mathrm{z}$ 461) presented MS2 fragments at $\mathrm{m} / \mathrm{z} 357,327,285$ and 115 , suggesting the presence of luteolin 7-0-glucuronide[35]. L3'S ([M - H]- at m/z 365) showed a MS2 fragmentation at m/z 285 and 257, associated with the chemical structure of luteolin O-sulfate. LUT ([M - H]- at m/z 285) showed the typical product-ions from the fragmentation of luteolin aglycone: $m / z$ at 257 , 241, 199, 175, 151 and 133 [7]. CHR and DIO exhibited the same parent-ion ([M - H] - at m/z 299), and very similar fragmentation patterns: $\mathrm{m} / \mathrm{z}$ at 284, 255, 151, 132, 107 and 284, 255, 179, 151, 107 , respectively; indicating the presence of 0-methylated luteolin derivatives, chrysoeriol and diosmetin, respectively [36,37]. Since the method was not validated to L3'S due to the unavailability of standard, this analyte was quantified expressing the results in equivalents of L7G. In fact, this is an approach often employed by other authors [38,39].

Globally, the present pharmacokinetic study, in plasma and tissues, revealed the presence ofLUT, L7G, CHR, DIO and also L3'S (Figure 1), while CAF, COU, ISV and ISO were not detected by the validated bioanalytical method, in all matrices. 
<smiles>COc1cc(-c2cc(=O)c3c(O)cc(O)cc3o2)ccc1O</smiles><smiles>COc1ccc(-c2cc(=O)c3c(O)cc(O)cc3o2)cc1O</smiles>

Figure1: Molecular structures of luteolin (LUT) and derivatives (isoorientin, ISO; chrysoeriol, CHR; diosmetin, DIO; luteolin 7-0-glucuronide, L7G; luteolin 3'-0-sulfate, L3'S).

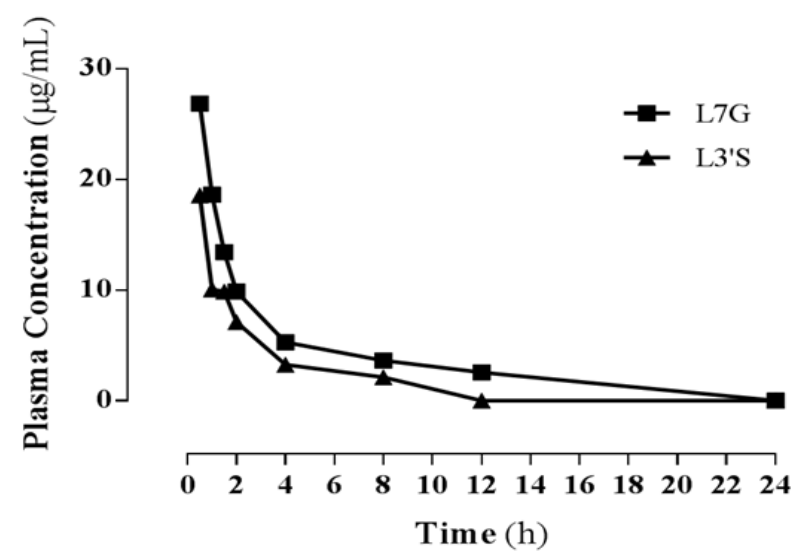

Figure 2: Plasma concentration-time profiles of luteolin 7-0-glucuronide (L7G) and luteolin 3'-0-sulfate (L3'S) obtained after administering a single oral dose of CcI extract to rats $(68.24 \mathrm{mg} / \mathrm{kg}) . S y m b o l s ~ r e p r e s e n t$ the mean values \pm standard error of the mean of six determinations per time point $(n=6)$

Table 2: Pharmacokinetic parameters of luteolin 7-O-glucuronide (L7G) luteolin 3'-O-sulfate (L3'S), in rat plasma after oral administration of the CcI extract at $68.24 \mathrm{mg} / \mathrm{kg}$ (mean \pm standard deviation, $n=6$ )

\begin{tabular}{|c|l|l|}
\hline \multirow{2}{*}{ Pharmacokinetic Parameters } & \multicolumn{2}{|c|}{ Compounds } \\
\cline { 2 - 3 } & \multicolumn{1}{|c|}{ L7G } & \multicolumn{1}{c|}{ L3'S } \\
\hline $\mathrm{C}_{\max }(\mathrm{mg} / \mathrm{mL})$ & $26.87 \pm 0.89$ & $18.57 \pm 0.31$ \\
\hline $\mathrm{T}_{\text {max }}(\mathrm{h})$ & $0.50 \pm 0.00$ & $0.50 \pm 0.00$ \\
\hline $\mathrm{T}_{1 / 2}(\mathrm{~h})$ & $7.61 \pm 0.34$ & $3.03 \pm 0.13$ \\
\hline $\mathrm{AUC}_{(0 \rightarrow \mathrm{t})}(\mathrm{h} \mathrm{mg} / \mathrm{mL})$ & $77.34 \pm 2.26$ & $41.95 \pm 1.11$ \\
\hline $\mathrm{AUC}_{(0 \rightarrow \infty)}(\mathrm{h} \mathrm{mg} / \mathrm{mL})$ & 105.36 & $51.22 \pm 1.37$ \\
& \pm 2.79 & \\
\hline $\mathrm{MRT}_{(0 \rightarrow \infty)}(\mathrm{h})$ & $3.77 \pm 0.04$ & $2.57 \pm 0.03$ \\
\hline
\end{tabular}

Although L7G and L3'S are not present in CcI, they were the only ones quantified in rat plasma. The plasma concentration-time profiles of the analytes found and quantified in rat plasma are shown in Figure 2 and the corresponding estimated pharmacokinetic parameters are listed in Table 2.Taking them together, it becomes evident that L7G and L3'S rapidly reached $\mathrm{T}_{\text {max }}$, with maximum concentrations at $30 \mathrm{~min}$ after oral administrations of CcI extract. Since they are not present in the initial extract and they quickly reach the $C_{\max }$ it can be possible to infer that the parent compounds are rapidly metabolized, probably in the gut and liver, before reaching the systemic blood flow. In fact, it is known that, at the intestinal tract, luteolin glycosides are hydrolyzed to luteolin, which is rapidly metabolized to glucuronides and sulfates by UDP-glucuronosyltransferases (UGTs), sulfotransferases (SULTs) and/or microbiota enzymes [40,41]. Moreover, luteolin is also described as being rapidly metabolized to L7G by UGTs, or to L3'S by SULTs in the liver [40]. Although plasma concentrationtime profiles for L7G and L3'S are almost parallel (Figure 2), their pharmacokinetic parameters in plasma after oral administration of $C$. citratus extract revealed to be slightly different from each other (Table 2), with L7G presenting higher values of $C_{\text {max }}$ AUC, $\mathrm{T}_{1 / 2}$ and MRT. These findings, suggest not only a higher biodisposition in plasma but also that L7G remains for a longer period of time in the organism. These data are in accordance with previous works regarding the plasma pharmacokinetics of similar compounds, such as vitexin 2"-O-rhamnoside, vitexin 4"-0-glucoside, luteolin 3'-0-glucuronide, apigenin 7-0-glucuronide and acacetin 7 -0-glucuronide [28,30,42]. As for the L3'S, it was already reported as being a major ISO metabolite in rats [43].

Besides L7G and L3'S, the analysis of liver tissue samples, revealed the presence of compounds undetected in plasma, namely LUT, CHR and DIO. The respective concentration-time profiles and pharmacokinetic parameters of the five analytes are displayed in Figure 3 and Table 3, respectively. According to $C_{\max }$ and AUC values, it becomes clear that the three major metabolites found in liver tissues were L7G, CHR and L3'S, which were detected from the first hour and remained in the tissue up to at least $24 \mathrm{~h}$. In opposition, DIO was detected only $8 \mathrm{~h}$ post-dosing, exhibiting the lowest concentration of all the analytes studied, suggesting that it is a minor product of rat metabolism. Therefore, it is not expected to contribute significantly to the pharmacological effects of the CcI extract in spite of exhibiting pharmacological activity in other studies when highly bioavailable in vivo [44].

The earlier $\mathrm{T}_{\max }$ values found in plasma rather than in liver, suggest that these metabolites are mainly produced at the small intestine level rather than in the liver. Similarly, Courts \& Williamson recently reported that flavones C-glycosides (e.g. vitexin, isoorientin and mangiferin) are promptly metabolized by gut microbiota and enterocytes enzymes [45].This may explain the very low bioavailability of luteolin aglycone herein found. 

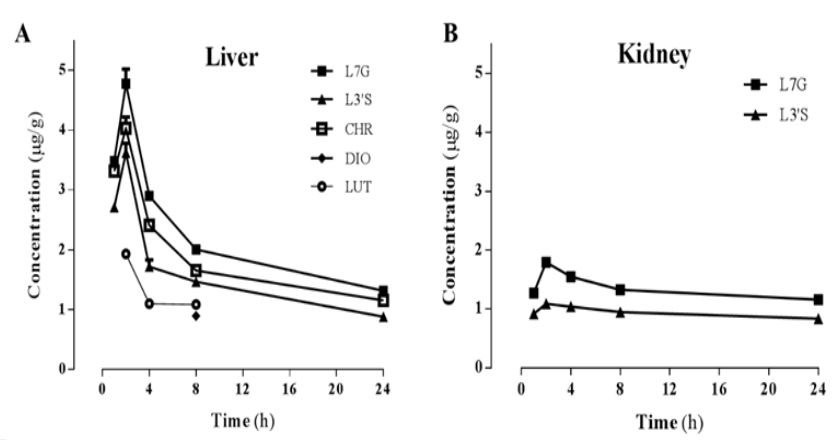

Figure 3: Liver (A) and kidney (B) concentration-time profiles of luteolin 7-O-glucuronide (L7G) luteolin 3'-O-sulfate (L3'S), chrysoeriol (CHR), diosmetin (DIO) and luteolin (LUT) obtained after administering a single oral dose of CcI extract $(68.24 \mathrm{mg} / \mathrm{kg})$ to rats. Symbols represent the mean values \pm standard error of the mean of two determinations per time point $(\mathrm{n}=2)$.

The kidney concentration-time profile revealed the presence of the same compounds detected in plasma, L7G and L3'S (Figure 3), probably due to their high concentrations in plasma. The pharmacokinetic parameters (Table 3) of these analytes are very similar, $\mathrm{L} 7 \mathrm{G}$ presenting higher $\mathrm{C}_{\max }$ and $\mathrm{AUC}$ values, but slightly lower $\mathrm{T}_{1 / 2}$ and MRT values than L3'S.
The pharmacokinetic analysis herein performed in plasma, liver and kidney showed that the compounds present in CcI $[4,6,11,14,15]$ are not abundant in plasma, liver or kidneys after a $68.24 \mathrm{mg} / \mathrm{kg}$ single-dose oral administration of the extract. In fact, the metabolites, L7G and L3'S,were the most abundant in plasma, particularly L7G which presented the highest AUC values, and, therefore, they are probably the main responsible for the anti-inflammatory activity previously reported [16]. Importantly it seems that, during the inflammatory process, the enzyme, -glucosidase over expressed by neutrophils leads to the deglucuronidationof L7G to LUT, which, in turn, exerts the biological effect when reaching the target-tissue [46-49].Therefore, L7G and L3'S seems to be the main active circulating forms of the aglycone luteolin.

The work herein exposed revealed, for the first time, how luteolin C-glycosides are metabolized in vivo after CcI administration to rats, and which are the main metabolites probably responsible for the CcI pharmacological effects previously observed in vivo [16].

Table 3: Pharmacokinetic parameters in rat liver and kidney after p.o. administration at $68.24 \mathrm{mg} / \mathrm{kg}$ (mean \pm standard deviation, $n=2$ )

\begin{tabular}{|c|c|c|c|c|c|c|}
\hline & $\begin{array}{c}C_{\max } \\
(\mathrm{mg} / \mathrm{g})\end{array}$ & $\begin{array}{l}T_{\max } \\
\text { (h) }\end{array}$ & $\begin{array}{l}T_{1 / 2} \\
\text { (h) }\end{array}$ & $\begin{array}{l}\operatorname{AUC}_{(0 \rightarrow \mathrm{t})} \\
(\mathrm{h} \mu \mathrm{g} / \mathrm{g})\end{array}$ & $\begin{array}{c}\text { AUC }_{(0 \rightarrow \infty)} \\
(\mathbf{h} \mu \mathrm{g} / \mathrm{g})\end{array}$ & $\begin{array}{c}\text { MRT }_{(0 \rightarrow \infty)} \\
\text { (h) }\end{array}$ \\
\hline \multicolumn{7}{|l|}{ Liver } \\
\hline L7G & $4.78 \pm 0.35$ & $2.00 \pm 0.00$ & $19.40 \pm 0.51$ & $49.90 \pm 1.26$ & $86.70 \pm 0.11$ & $9.30 \pm 0.10$ \\
\hline L3'S & $3.62 \pm 0.23$ & $2.00 \pm 0.00$ & $21.60 \pm 5.08$ & $35.00 \pm 0.55$ & $62.71 \pm 7.74$ & $9.21 \pm 0.25$ \\
\hline CHR & $4.03 \pm 0.27$ & $2.00 \pm 0.00$ & $21.20 \pm 0.89$ & $42.40 \pm 1.53$ & $77.80 \pm 4.95$ & $6.94 \pm 0.08$ \\
\hline DIO & $0.89 \pm 0.04$ & $8.00 \pm 0.00$ & $\mathrm{NC}$ & NC & $\mathrm{NC}$ & $8.00 \pm 0.00$ \\
\hline LUT & $1.93 \pm 0.01$ & $2.00 \pm 0.00$ & $8.38 \pm 0.39$ & $8.37 \pm 0.18$ & $21.50 \pm 1.21$ & $4.35 \pm 0.02$ \\
\hline \multicolumn{7}{|l|}{ Kidney } \\
\hline L7G & $1.80 \pm 0.01$ & $2.00 \pm 0.00$ & $54.61 \pm 4.38$ & $31.14 \pm 0.39$ & $122.63 \pm 9.94$ & $11.37 \pm 0.09$ \\
\hline L3'S & $1.09 \pm 0.00$ & $2.00 \pm 0.00$ & $68.88 \pm 2.08$ & $21.83 \pm 0.29$ & $104.88 \pm 4.41$ & $11.58 \pm 0.05$ \\
\hline
\end{tabular}

\section{Conclusions}

In conclusion, to the best of our knowledge, this work is the first report documenting the quantification of LUT, L7G, L3'S, CHR and DIO in rat plasma, liver and/or kidney, after the oral administration of a single dose of $C$. citratus infusion. This work has successfully investigated the pharmacokinetics of $\mathrm{CcI}$ in rats, and could also be applied in future studies of lemongrass preparations. The pharmacokinetics of the two major luteolin conjugates in vivo (L7G and L3'S) herein obtained support the pharmacological effects of $C$. citratus in vivo.

\section{Acknowledgements}

The authors thank ERVITAL ${ }^{\circledR}$ for providing the plant material. Work supported by FEDER/COMPETE (FCOMP-010124-FEDER-011096) and Foundation for Science and Technology (FCT), by the projects PTDC/SAU-FCF/105429/2008 and PEst-OE/SAU/UI0177/2014. The authors also thank to LEM-UC (Laboratory of Mass Spectrometry, University of Coimbra) node integrated in the National Mass Spectrometry Network (RNEM) of Portugal, for the mass spectrometry analyses. 


\section{References}

1. AA Adeneye, EO Agbaje. Hypoglycemic and hypolipidemic effects of fresh leaf aqueous extract of Cymbopogon citratus Stapf in rats. J Ethnopharmacol. 2007;112(3):440-444.

2. A Tapia, J Cheel, C Theoduloz, J Rodríguez, G Schmeda-Hirschmann, A Gerth, et al. Free radical scavengers from Cymbopogon citratus (DC.) stapf plants cultivated in bioreactors by the temporary immersion (TIS) principle. Z Naturforsch C. 2007;62(5-6):447-457.

3. Campos J, Schmeda-Hirschmann G, Leiva E, Guzmán L, Orrego R, Fernández P, et al. Lemon grass (Cymbopogon citratus (D.C) Stapf) polyphenols protect human umbilical vein endothelial cell (HUVECs) from oxidative damage induced by high glucose, hydrogen peroxide and oxidised low-density lipoprotein. Food Chem. 2014;151:175-181.

4. R Orrego, E Leiva, J Cheel. Inhibitory effect of three C-glycosylflavonoids from Cymbopogon citratus (Lemongrass) on human low density lipoprotein oxidation. Molecules. 2009;14(10):3906-3913.

5. E Salim, E Kumolosasi, I Jantan. Inhibitory effect of selected medicinal plants on the release of pro-inflammatory cytokines in lipopolysaccharide-stimulated human peripheral blood mononuclear cells. J Nat Med. 2014;68(3):647-653.

6. Figueirinha A, Paranhos A, Pérez-Alonso JJ, Santos-Buelga C, Batista MT. Cymbopogon citratus leaves: Characterization of flavonoids by HPLC-PDA-ESI/MS/MS and an approach to their potential as a source of bioactive polyphenols. Food Chem. 2008;110(3):718-728.

7. Roriz CL, Barros L, Carvalho AM, Santos-Buelga C, Ferreira ICFR. Pterospartum tridentatum, Gomphrena globosa and Cymbopogon citratus: A phytochemical study focused on antioxidant compounds. Food Res Int. 2014;62:684-693.

8. MO Soares, RC Alves, PC Pires, MBPP Oliveira, AF Vinha. Angolan Cymbopogon citratus used for therapeutic benefits: nutritional composition and influence of solvents in phytochemicals content and antioxidant activity of leaf extracts. Food Chem Toxicol. 2013;60:413-418.

9. M Tiwari, UN Dwivedi, P Kakkar. Suppression of oxidative stress and pro-inflammatory mediators by Cymbopogon citratus D. Stapf extract in lipopolysaccharide stimulated murine alveolar macrophages. Food Chem Toxicol. 2010;48(10):2913-2919.

10. G Costa, F Nunes, C Vitorino, MT Batista, I Vitória, et al. Validation of a RP-HPLC Method for Quantitation of Phenolic Compounds in three Different Extracts from Cymbopogon citratus. Res. J. Med. Plant. 2015;9(7):331-339.

11. A Figueirinha, MT Cruz, V Francisco, MC Lopes, MT Batista. Anti-inflammatory activity of Cymbopogon citratus leaf infusion in lipopolysaccharide-stimulated dendritic cells: contribution of the polyphenols. J Med Food. 2010;13(3):681-690.

12.V Francisco, A Figueirinha, BM Neves, C García-Rodríguez, MC Lopes, MT Cruz, et al. Cymbopogon citratus as source of new and safe antiinflammatory drugs: bio-guided assay using lipopolysaccharide-stimulated macrophages. J Ethnopharmacol. 2011;133(2):818-827.

13. Francisco V, Costa G, Figueirinha A, Marques C, Pereira P, Miguel Neves B, et al. Anti-inflammatory activity of Cymbopogon citratus leaves infusion via proteasome and nuclear factor- $\mathrm{\kappa B}$ pathway inhibition: contribution of chlorogenic acid. J Ethnopharmacol. 2013;148(1):126134.

14. Francisco V, Figueirinha A, Costa G, Liberal J, Lopes MC, García-Ro- dríguez C, et al. Chemical characterization and anti-inflammatory activity of luteolin glycosides isolated from lemongrass. J Funct Foods. 2014;10:436-443.

15. Costa G, González-Manzano S, González-Paramás A, Figueiredo IV, Santos-Buelga C, Batista MT. Flavan hetero-dimers in the Cymbopogon citratus infusion tannin fraction and their contribution to the antioxidant activity. Food Funct. 2015;6(3):932-937.

16. Garcia R, Pinto Ferreira J, Costa G, Santos T, Branco F, Caramona M, et al. Evaluation of anti-inflammatory and analgesic activities of Cymbopogon citratus in vivo - polyphenols contribution. Res. J. Med. Plant. 2015;9(1):1-13.

17. Rice-Evans C. Flavonoids and isoflavones: Absorption, metabolism, and bioactivity. Free Radic Biol Med. 2004;36(7):827-828.

18. Marín L, Miguélez EM, Villar CJ, Lombó F. Bioavailability of Dietary Polyphenols and Gut Microbiota Metabolism : Antimicrobial Properties. Biomed Res Int. 2015;2015:905215.

19. Gee JM, DuPont MS, Day AJ, Plumb GW, Williamson G, Johnson IT. Intestinal transport of quercetin glycosides in rats involves both deglycosylation and interaction with the hexose transport pathway. J Nutr. 2000;130(11):2765-2771.

20. Ouzzine M, Barré L, Netter P, Magdalou J, Fournel-Gigleux S. The human UDP-glucuronosyltransferases: structural aspects and drug glucuronidation. Drug Metab. Rev. 2003;35(4):287-303.

21. Selma MV, Espín JC, Tomás-Barberán FA. Interaction between phenolics and gut microbiota: role in human health. J Agric Food Chem. 2009 Aug 12;57(15):6485-6501.

22. Chen Z, Chen M, Pan H, Sun S, Li L, Zeng S, et al. Role of Catechol-OMethyltransferase in the Disposition of Luteolin in Rats. Drug Metab Dispos. 2011;39(4):667-74.

23. Cardona F, Andrés-Lacueva C, Tulipani S, Tinahones FJ, Queipo-Ortuño MI. Benefits of polyphenols on gut microbiota and implications in human health. J. Nutr. Biochem. 2013;24(8):1415-1422.

24.Xue HF, Ying ZM, Zhang WJ, Meng YH, Ying XX, Kang TG. Hepatic, gastric, and intestinal first-pass effects of vitexin in rats. Pharm Biol. 2014;52(8):967-71.

25. Sheng N, Zhi X, Yuan L, Zhang Z, Jia P, Zhang X, et al., Pharmacokinetic and excretion study of three secoiridoid glycosides and three flavonoid glycosides in rat by LC-MS/MS after oral administration of the Swertia pseudochinensis extract. J Chromatogr B Anal Technol Biomed Life Sci. 2014;967:75-83.

26. Y Zhang, X Tie, B Bao, X Wu, Y Zhang. Metabolism of flavone C-glucosides and p-coumaric acid from antioxidant of bamboo leaves (AOB) in rats. Br J Nutr. 2007;97(3):484-494.

27. LY Ma, RH Liu, XD Xu, MQ Yu, Q Zhang, HL Liu. The pharmacokinetics of C-glycosyl flavones of Hawthorn leaf flavonoids in rat after single dose oral administration. Phytomedicine. 2010;17(8-9):640-645. doi: 10.1016/j.phymed.2009.12.010

28.W Zhang, M Xu, C Yu, G Zhang, X Tang. Simultaneous determination of vitexin-4"-0-glucoside, vitexin-2"-0-rhamnoside, rutin and vitexin from hawthorn leaves flavonoids in rat plasma by UPLC-ESI-MS/MS. J Chromatogr B Analyt Technol Biomed Life Sci. 2010;878(21):18371844. doi: 10.1016/j.jchromb.2010.05.023

29. JK Prasain, K Jones, N Brissie, R Moore, JM Wyss, S Barnes. Identification of puerarin and its metabolites in rats by liquid chromatography- 
tandem mass spectrometry. J Agric Food Chem. 2004;52(12):37083712.

30. M Liang, W Xu, W Zhang, C Zhang, R Liu, Y Shen, et al. Quantitative LC/MS/MS method and in vivo pharmacokinetic studies of vitexin rhamnoside, a bioactive constituent on cardiovascular system from hawthorn. Biomed Chromatogr. 2007;21(4):422-429.

31. US DHHS, FDA. Guidance for Industry - Estimating the maximum safe starting dose in initial clinical trials for therapeutics in adult healthy volunteers. Pharmacology and Toxicology. 2005;1-30.

32.FDA. Guidance for Industry Bioanalytical Method Validation. 2013.

33. EMA. Guideline on bioanalytical method validation. Eur Med Agency. 2011;1-23.

34. F Tavares, G Costa, V Francisco, J Liberal, A Figueirinha, MC Lopes, et al. Cymbopogon citratus industrial waste as a potential source of bioactive compounds. J Sci Food Agric. 2015;95(13):2652-2659.

35. R Yin, F Han, Z Tang, R Liu, X Zhao, X Chen, et al. UFLC-MS/MS method for simultaneous determination of luteolin-7-0-gentiobioside, luteolin-7-0-d-glucoside and luteolin-7-0-d-glucuronide in beagle dog plasma and its application to a pharmacokinetic study after administration of traditional Chinese medicin. J Pharm Biomed Anal. 2013;72:127-133.

36. A Brito, JE Ramirez, C Areche, B Sepúlveda, MJ Simirgiotis. HPLC-UVMS Profiles of Phenolic Compounds and Antioxidant Activity of Fruits from Three Citrus Species Consumed in Northern Chile. Molecules. 2014;19(11):17400-17421.

37. H Radwan, A Hamdy. Phytochemical constituents of Arthrocnemum glaucum (Del.) and their biological activities. AGRIS. 2006.

38. S Granica, H Kluge, G Horn, A Matkowski, AK Kiss. The phytochemical investigation of Agrimonia eupatoria L and Agrimonia procera Wallr. as valid sources of Agrimoniae herba - The pharmacopoeial plant material. J Pharm Biomed Anal. 2015;114:272-279.

39. Y Kiselova, D Ivanova, T Chervenkov, D Gerova, B Galunska, Yankova T, et al. Correlation between the In Vitro Antioxidant Activity and Polyphenol Content of Aqueous Extracts from Bulgarian Herbs. Phyther Res. 2006;20(11):961-965.
40. FA Tomás-Barberán, C Andrés-Lacueva. Polyphenols and health: current state and progress. J Agric Food Chem. 2012;60(36):8773-8775.

41. BD Davis, JS Brodbelt. Regioselectivity of Human UDP-Glucuronosyltransferase $1 \mathrm{~A} 1$ in the Synthesis of Flavonoid Glucuronides Determined by Metal Complexation and Tandem Mass Spectrometry. J Am Soc Mass Spectrom. 2008;19(2):246-256.

42.L Qiang, W Liping, D Peimin, Z Xuejun, Q Xiaoxiao, Z Lijun, et al. A combined strategy of mass fragmentation, post-column cobalt complexation and shift in ultraviolet absorption spectra to determine the uridine 5 -diphospho-glucuronosyltransferase metabolism profiling of flavones after oral administration of a flavone mixture in rats. J Chromatogr A. 2015; 1395:116-128.

43. P Shi, X Lin, H Yao. Metabolism and plasma pharmacokinetics of isoorientin, a natural active ingredient, in Sprague-Dawley male rats after oral and intravenous administration. Xenobiotica. 2015;45(11):9991008.

44. K Patel, M Gadewar, V Tahilyani, DK Patel. A Review on Pharmacological and Analytical Aspects of Diosmetin : A Concise Report. Chin J Integr Med. 2013;19(10):792-800.

45. FL Courts, G Williamson. The occurrence, fate and biological activities of C -glycosyl flavonoids in the human diet. Crit Rev Food Sci Nutr. 2013;1352-1367.

46. K Shimoi, Noriko Saka, Ryushi Nozawa, Motoyoshi Sato, Izumi Amano, Tsutomu Nakayama, et al. Deglucuronidation of a flavonoid, luteolin monoglucuronide, during inflammation. Drug Metab. Dispos. 2001;29(12):1521-1524.

47. D Chen, A Bi X Dong, Y Jiang, B Rui, J Liu, et al. Luteolin exhibits antiinflammatory effects by blocking the activity of heat shock protein 90 in macrophages. Biochem Biophys Res Commun. 2014;443(1):326332.

48. S Lamy, PL Moldovan, A Ben Saad, B Annabi. Biphasic effects of luteolin on interleukin-1 $\beta$-induced cyclooxygenase- 2 expression in glioblastoma cells. Biochim Biophys Acta. 2015;1853(1):126-135.

49. K Shimoi, N Saka, K Kaji, R Nozawa, N Kinae. Metabolic fate of luteolin and its functional activity at focal site. Biofactors. 2000;12(1-4):181- 